\title{
Levetiracetam Versus Sodium Valproate in Refractory Convulsive Status Epilepticus in Children: An Open Randomized Trial
}

\author{
Rajniti Prasad ${ }^{1 *}$, Astha Panghal ${ }^{1}$, Ankur Singh ${ }^{1}$, OP Mishra ${ }^{1}$ and TB \\ Singh ${ }^{2}$ \\ ${ }^{1}$ Department of Pediatrics, Institute of Medical Sciences, Banaras Hindu University, \\ Varanasi, India \\ ${ }^{2}$ Division of Biostatistics, Institute of Medical Sciences, Banaras Hindu University, \\ Varanasi, India
}

*Corresponding Author: Rajniti Prasad, Professor and Head, Department of Pediatrics, Institute of Medical Sciences, Banaras Hindu University, Varanasi, India.
Received: March 21, 2021

Published: March 29, 2021

(c) All rights are reserved by Rajniti Prasad., et al.

\begin{abstract}
Purpose: Levetiracetam (LEV) is a safe and effective drug to control status epilepticus (SE) or refractory status epilepticus (RSE) in adults. However, there is discernible lack of evidence of its use in children and adolescents. There is dearth of randomized trials comparing its efficacy with sodium valproate (VPA) in children. We performed an open randomized study to determine efficacy of LEV as an alternative to VPA in treatment of RSE.

Methods: We randomized 80 children aged 1 to 16 years with SE not responding to any two of the first line drugs in adequate doses, into two drug groups LEV ( $\mathrm{n}=40)$ and VPA $(\mathrm{n}=40)$. Primary end point was cessation of seizure activity within 30 minutes. Response of the two drug groups were compared at 30 minutes, $24 \mathrm{hrs}$, discharge and one month follow up.

Results: At 30 minutes, cessation of convulsion occurred in 29 patients (72.5\%) in LEV and 23 patients (57.5\%) in VPA group (n = $40, p=0.241)$. At 24 hours of administration, seizure was controlled in 66.7\% $(n=36)$ in LEV and 68.4\% ( $n=38)$ in VPA group. LEV was as effective as VPA in controlling RSE ( $p=0.872)$. No serious adverse effects were observed in both groups.

Conclusion: Intravenous LEV is as effective as VPA in control of RSE and well tolerated in children. LEV can be considered as first line drug to control RSE in children before induction of general anaesthesia.
\end{abstract}

Keywords: Status Epilepticus (SE); Refractory Status Epilepticus (RSE); Levetiracetam (LEV); Sodium Valproate (VPA)

\section{Introduction}

Refractory status epilepticus (RSE) is a life threatening pediatric neurological emergency. Status epilepticus (SE) should be considered refractory when either clinical or electrographic seizures persist after receiving two anti-epileptic drug (AED) in adequate doses, the usual combination being benzodiazepine followed by phenytoin or phenobarbital [1,2]. Various studies have reported prevalence of RSE from $11 \%$ to $43 \%$ [3-8]. It is usually accompanied by higher mortality and morbidity rates [4].

The stepwise treatment of SE and RSE is based on studies, mostly performed in adults, and at a time when intravenous (IV) medications and options were limited. The preferred first-line therapy is usually a benzodiazepine, commonly lorazepam. There are few controlled studies that have compared the efficacy of first-line treatments for SE, but majority of them have either not included children [6,7] or children represented only a minor proportion. Till date, various randomized trials have been performed with first line drug (Lorazepam, diazepam, midazolam, phenytoin and phenobarbital) $[8,9]$. Several randomized studies have compared second line agent VPA with first line drugs [10-13], but these studies included either pediatric or mixed population. Efficacy of $70-100 \%$ has been reported with loading doses of $20-40 \mathrm{mg} / \mathrm{kg}$ in children [13].

Levetiracetam (LEV) is a newer second generation anti-epileptic drug with linear pharmacokinetic profile, minimal plasma protein binding, negligible drug interactions and lack of hepatic metabolism [14]. It is a safe and effective option for RSE but, data supporting its use in children is primarily extrapolated from retrospective studies and case reports including neonatal, partial and generalized seizures [13-22]. Well designed clinical trials supporting its 
efficacy in RSE are lacking [23]. Therefore, we had conducted an open label randomized study to determine the efficacy of LEV as an alternative to sodium valproate (VPA) and compared its efficacy and safety in treatment of RSE.

\section{Methods}

\section{Patient recruitment and treatment}

The present study was conducted in Pediatric intensive care unit of Department of Pediatrics, Institute of Medical Sciences from January 2016 to December 2018. Ethics committee of Institute has approved the study protocol. Children had been enrolled after obtaining consent from parent or legal guardian of patients.

\section{Inclusion criteria and randomization}

We recruited children from 1 to 16 years presenting with SE, who were still having active convulsions despite receiving intravenous (IV) lorazepam at a dose of $0.1 \mathrm{mg} / \mathrm{kg}$ ( $\mathrm{max} 4 \mathrm{mg}$ ) and intravenous phenytoin at a dose of $20 \mathrm{mg} / \mathrm{kg}$ at a rate of $1 \mathrm{mg} / \mathrm{kg} / \mathrm{min}$ ute. After labelling these children with active convulsions as RSE and obtaining a written informed consent from parents, they were randomized into two equal groups. Patients were randomized by computer generated block randomization and method of concealment by sequentially numbered, sealed and opaque envelopes in two groups.

- Group I: Intravenous (IV) LEV $30 \mathrm{mg} / \mathrm{kg}$ bolus (repeated second dose if no control) followed by $30 \mathrm{mg} / \mathrm{kg} / \mathrm{dose}$ IV 12 hourly

- Group II: Intravenous (IV) VPA $20 \mathrm{mg} / \mathrm{kg}$ bolus followed by $10 \mathrm{mg} / \mathrm{kg} /$ dose IV 8hrly or $5 \mathrm{mg} / \mathrm{kg} / \mathrm{hr}$ as intravenous infusion. Levocarnitine $(50 \mathrm{mg} / \mathrm{kg} /$ day) was given to all children below 2 years of age.

We changed the therapy if life-threatening seizures were continued as per the standard protocol of Indian Academy of Pediatrics as summarized in figure 1 [24]. Detailed patient history and relevant details like seizure type, duration, vital signs, response to intervention were recorded. All patients were monitored for vital signs and convulsive activity till completion of 24 hour study period.

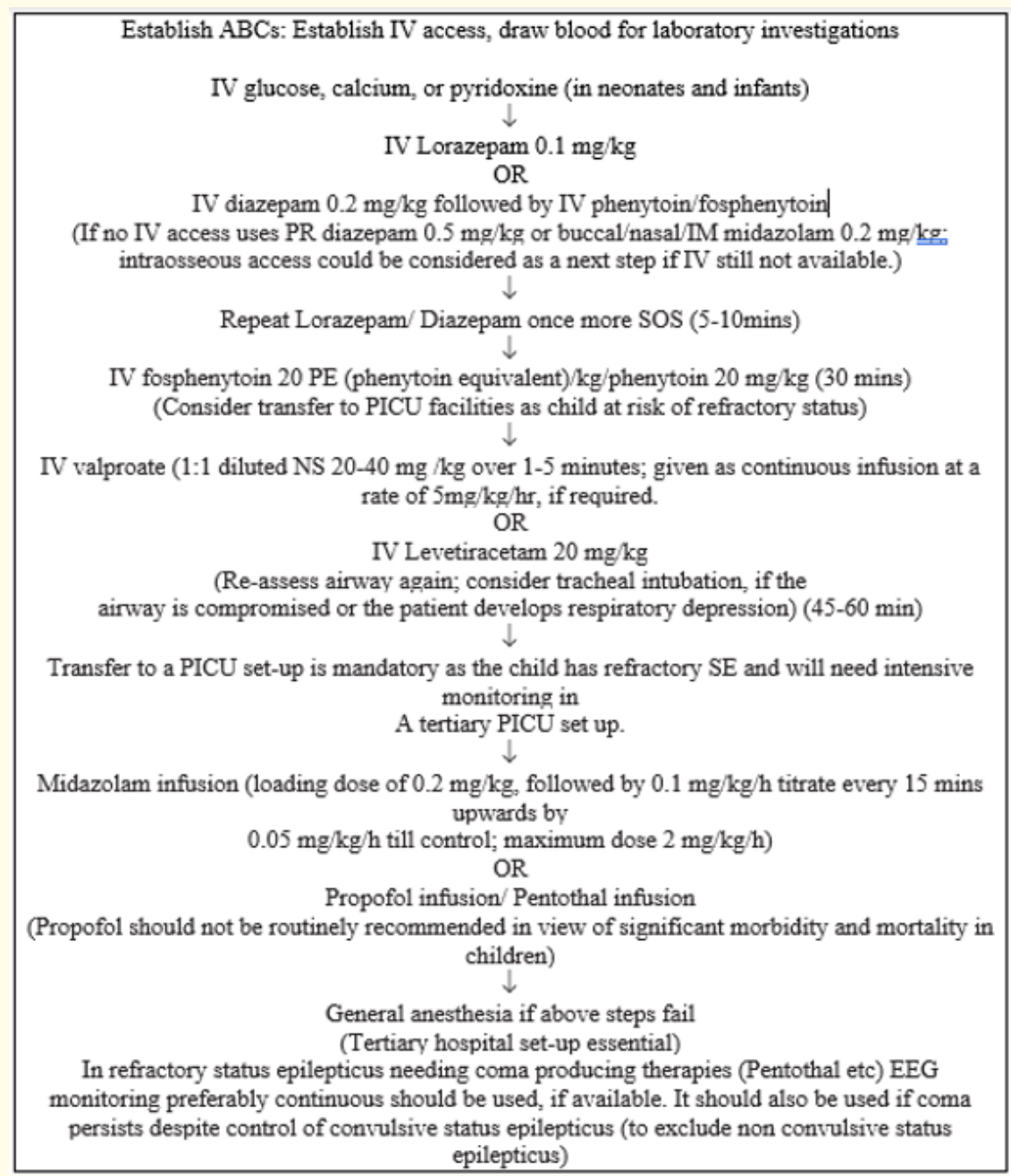

Figure 1: Protocol for management of childhood convulsive status epilepticus [24]. 


\section{Exclusion criteria}

Patients with epilepsia partialis continua and patients with definite history of any allergic reaction to intravenous LEV or VPA, or any contraindications such as liver disease, inborn error of metabolism were excluded.

Appropriate laboratory investigations (Complete Blood Count, electrolytes, Arterial blood gas analysis, Liver Function Test, Renal Function Test, CSF study) and imaging of enrolled patients were done to find out the etiology.

\section{End points}

The primary end point was clinical termination of seizure activity within 30 min after initiation of drug infusion. The secondary end points included control of seizures after 24 hours of administration, recurrence of seizures within 24 hours, drug related adverse effects, requirement of additional anti-epileptic drugs, mortality during hospitalization, length of hospital stay, seizure outcome at discharge and follow-up, and neurological outcome.

\section{Statistical analysis}

The data was analysed using SPSS version 20.0 software. The safety and efficacy of two drugs in each group were studied and the response was compared between the two groups in terms of significance using Wilcoxon rank sum test or student t-test (for quantitative data) and Chi-square test (for qualitative data) whichever applicable. $P$ value of $<0.05$ is taken as statistically significant for analysis.

\section{Results}

Out of 98 patients who were assessed for eligibility, 80 met the inclusion criteria and were randomized into two drug groups (Figure 2). Baseline characteristics for both groups are presented in table 1 . The mean age of children in group-I and II was $4.6 \pm 4.1$ and $5.1 \pm 4.2$ yrs. Majority of children were in age group 1 to 3 years (43.7\%) followed by 3 to $6(26.2 \%)$ years. Thirty six (90\%) patient in group I and 38 (95\%) in group II presented with Tonic Clonic Seizure, others had tonic seizures. Most of the patients in group I, $24(60 \%)$ had duration of seizure episode at presentation between 2-5 (mean: $6.35 \pm 1.8$ ) hrs and in group II, 18 (45\%) >5 (mean:6.6 \pm 1.1) hrs. Among known epileptic patients, phenytoin monotherapy was common.

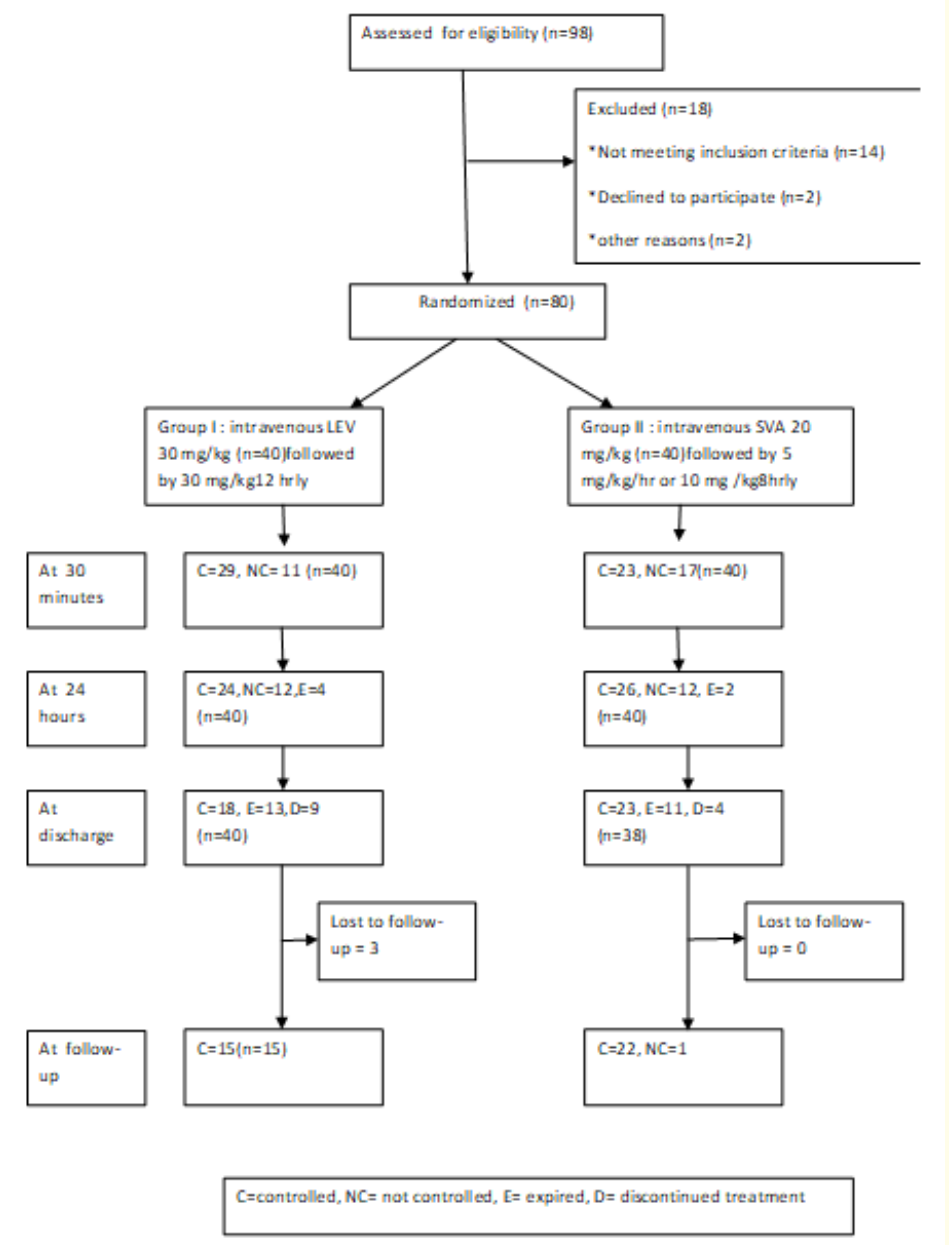

Figure 2 


\begin{tabular}{|l|c|c|c|}
\hline & Group-I (n = 40) & Group-II (n = 40) & p-value \\
\hline Age (yr) & $4.6 \pm 4.1$ & $5.1 \pm 4.2$ & 0.575 \\
\hline Sex (male) & $23(57.5 \%)$ & $25(62.5 \%)$ & 0.820 \\
\hline Presenting complaints & & & \\
\hline Fever & $38(95 \%)$ & $36(90 \%)$ & 0.675 \\
\hline Rash & $8(20 \%)$ & $4(10 \%)$ & 0.546 \\
\hline Headache & $8(20 \%)$ & $5(12.5 \%)$ & 0.546 \\
\hline Diarrhoea & $8(20 \%)$ & $8(20 \%)$ & 1.000 \\
\hline URTI & $8(20)$ & $3(7.5 \%)$ & 0.193 \\
\hline Vomiting & $9(22.5 \%)$ & $8(20 \%)$ & 1.000 \\
\hline Jaundice & $5(12.5 \%)$ & $6(15 \%)$ & 1.000 \\
\hline Mean duration of seizure at presentation (hrs) & $6.35 \pm 1.8$ & $6.6 \pm 1.1$ & 0.910 \\
\hline Type of seizure & & & \\
\hline Tonic clonic seizure & $36(90 \%)$ & $38(95 \%)$ & \\
\hline Tonic seizure & $4(10 \%)$ & $2(5 \%)$ & \\
\hline Prior use of AED & $8(20 \%)$ & $10(25 \%)$ & \\
\hline Cerebro Spinal Fluid Findings & & & \\
\hline Cells $^{\varphi}$ & $10(3-72)$ & $10(0-19)$ & 0.395 \\
\hline Protein ${ }^{\varphi}$ & $34(20.3-116)$ & $21.4(16.8-41.8)$ & 0.008 \\
\hline sugar ${ }^{\varphi}$ & $64(52-78)$ & $71(61.8-88.7)$ & 0.992 \\
\hline
\end{tabular}

Table 1: Baseline characteristics of study population.

$\varphi$ : Median with interquartile range.

Imaging studies could not be performed in all cases due to financial constraints. CT scan was done in 69 patients, findings were cerebral edema (9), hydrocephalus (3), hypoxic change (3), infarct (3), leucomalacia (1), cortical dysplasia (1), hemorrhage (1), pilocytic astrocytoma (1), corpus callosum agenesis (1) and gliosis (1). MRI brain was done in 11 patients, it showed hypoxic changes (3), white matter hyperintensity (3), hypomyelination (1), and lobar holoprosencephaly (1). EEG was done late in several patients and even carried out after control of seizures due to unavailability of EEG monitoring facility. EEG showed generalized abnormal waveform, high amplitude slow wave and high voltage paroxysmal bursts.

Etiological causes were divided into four groups: acute symptomatic (resulting from acute systemic, metabolic or toxic insult), prolonged febrile status, remote symptomatic: CNS insult more than one week resulting in a static lesion and idiopathic: certain epileptic syndromes without any obvious evidence of insult (Table 2). Acute symptomatic cause was commonest i.e. 33 (82.5) and 28 $(70 \%)$ in group I and II respectively followed by remote symptomatic. Among acute symptomatic, encephalitis (43.7\%) and meningitis (17.5\%) were common, others include metabolic disturbances (5), suspected hemorrhage (6) and drowning (1).
LEV and VPA effectively controlled seizure in 29 (72.5\%) and 23 patients $(57.5 \%)$ respectively within 30 minutes of infusion (pvalue $=0.241)$. At 24 hours, $24(66.7 \%)$ patients in group I and 26 (68.4) patients in group II remained controlled ( $p$-value $=0.872$ ), although seizure recurrence was present. There was no significant difference between the two groups regarding the cessation of seizure at $30 \mathrm{~min}$ and 24 hours, recurrence of seizure episode, requirement of additional anti-epileptics to control seizure and the time taken to control seizure. Eleven patients $(27.5 \%)$ in group I and 15 patients $(37.5 \%)$ in group II were crossed over and received the other drug, out of them 8 patients in group I and 9 patients in group II needed additional agents to control seizure. The commonest additional drug used was midazolam infusion (Table 3).

There was no significant change in vital parameters in any group after administering interventional agent. No serious adverse events were noted with any group. Three patients were lost to follow-up in group I and 1 patient in group II. All patients in group I had well controlled seizures but, in group II one patient needed additional anti-epileptic drug post-discharge to control seizure. Five patients in group I and 4 patients in group II were found to have neurological deficit at follow-up in the form of monoparesis, paraparesis and cranial nerve palsy. None of the children were found to have behavioural abnormalities. 


\begin{tabular}{|l|c|c|c|}
\hline Primary diagnosis & Group-I & Group-II & p-value \\
\hline Acute symptomatic & & & \\
\hline Encephalitis & $13(32.5 \%)$ & $22(55 \%)$ & 0.004 \\
Meningitis & $11(27.5 \%)$ & $3(7.5 \%)$ & 0.065 \\
ICH & $5(12.5 \%)$ & $1(2.5 \%)$ & 0.205 \\
Drowning & 0 & $1(2.5 \%)$ & 0.459 \\
Hypernatremia & $2(5 \%)$ & 0 & 0.495 \\
Hypocalcemia & $2(5 \%)$ & $1(2.5 \%)$ & 1.000 \\
\hline Prolonged Febrile status & $0(0 \%)$ & $1(2.5 \%)$ & 1.000 \\
\hline Remote symptomatic & & & \\
\hline Cerebral palsy & $2(5 \%)$ & $3(7.5 \%)$ & 0.545 \\
Hydrocephalus & 0 & $1(2.5 \%)$ & 1.000 \\
Sturge-Weber syndrome & 0 & $1(2.5 \%)$ & 1.000 \\
Corpus callosum agenesis & 0 & $1(2.5 \%)$ & 1.000 \\
Brain tumour & 0 & $1(2.5 \%)$ & 1.000 \\
Inborn error of metabolism & $1(2.5 \%)$ & $1(2.5 \%)$ & 1.000 \\
\hline Idiopathic & $4(10 \%)$ & $3(7.5 \%)$ & 1.000 \\
\hline
\end{tabular}

Table 2: Etiological profile of patients.

\begin{tabular}{|c|c|c|c|}
\hline & Group-I $(n=40)$ & Group-II $(n=40)$ & p-value \\
\hline \multicolumn{4}{|l|}{ Response to seizure at $30 \mathrm{~min}$} \\
\hline Controlled & $29(72.5 \%)$ & $23(57.5 \%)$ & 0.241 \\
\hline Not-controlled & $11(27.5 \%)$ & $17(42.5 \%)$ & \\
\hline Response to seizure at $24 \mathrm{hr}$ & $(n=36)$ & $(n=38)$ & 0.872 \\
\hline Controlled & $24(66.7 \%)$ & $26(68.4 \%)$ & \\
\hline Not-controlled & $12(33.3 \%)$ & $12(31.6 \%)$ & \\
\hline Mean time taken to control seizure (min) & $33.46 \pm 16.84$ & $37.25 \pm 19.93$ & 0.441 \\
\hline Patients requiring additional drugs to control seizure $(n=40)$ & $20(50 \%)$ & $23(57.5 \%)$ & 0.654 \\
\hline Additional number of drugs to control RSE & $2.27 \pm 0.63$ & $2.38 \pm 0.67$ & 0.546 \\
\hline Midazolam & 9 & 7 & \\
\hline Valproate & 3 & 0 & \\
\hline Valproate and midazolam & 7 & 0 & \\
\hline Valproate and topiramate & 1 & 0 & \\
\hline Levetiracetam & 0 & 6 & \\
\hline Levetiracetam and midazolam & 0 & 8 & \\
\hline Levetiracetam, midazolam and thiopentone sodium & 0 & 1 & \\
\hline Midazolam and thiopentone sodium & 0 & 1 & \\
\hline Crossed over patients & $11(27.5 \%)$ & $15(37.5 \%)$ & 0.474 \\
\hline Crossed over patients refractory at 24 hours & $5(12.5 \%)$ & $8(20 \%)$ & 0.709 \\
\hline Death & $13(32.5 \%)$ & $11(27.5 \%)$ & 0.502 \\
\hline Duration of stay (days) & $6.43 \pm 4.97$ & $7.75 \pm 5.5$ & 0.262 \\
\hline At 1 month follow-up & $\mathrm{N}=18$ & $\mathrm{~N}=23$ & \\
\hline Seizure controlled & $15(83.3 \%)$ & $22(95.6 \%)$ & 1.000 \\
\hline Neurological deficit & $5(27.7 \%)$ & $4(17.3 \%)$ & 0.322 \\
\hline
\end{tabular}

Table 3: Primary and secondary outcome.

RSE: Refractory status Epilepticus. 


\section{Discussion and Conclusion}

With the emerging need of randomized trials to support use of LEV in children with RSE because of its favourable pharmacokinetics, efficacy and tolerability, we conducted this open label randomized study including a modest sample size comparing LEV with VPA in a tertiary centre in Northern India. The mean age and sex distribution of our study was similar to previous studies [2,8,25]. Mean duration of the seizure episode at the time of presentation (Table 1) was higher than reported previously [26]. This could be due to lack of awareness among general public, inadequacy of the peripheral health care system and ignorance among the treating physicians. The commonest etiology in our study was acute symptomatic (76.25\%) followed by remote symptomatic (13.7\%), CNS infection was commonest in acute symptomatic category (43.7\%) which is comparable to etiological profile described in a recent study [25].

In our study, LEV was effective in controlling seizure within 30 min of infusion in $72.5 \%$ children, while VPA in $57.5 \%$ children, though the statistical difference was insignificant $(\mathrm{p}-$ value $=$ 0.241). Similar efficacy rates have been found in previous randomized trials on adult population, where LEV was compared against lorazepam as first line drug for SE (76.1\%) [27]. Another recent study describes a lower rate of cessation of seizure (68.1\%), when LEV was used as a second line agent [26]. A randomized study on children with partial-onset seizure observed response rate of $52 \%$ with LEV [27]. Among retrospective studies, efficacy rates between 50\%-78.2\% were observed when LEV was used for controlling acute seizure, acute repetitive seizure, epilepsy and refractory status epilepticus [15-22]. Randomized studies comparing VPA with first line agents have found efficacy rates between $15-30 \%$ with a loading dose of $20-30 \mathrm{mg} / \mathrm{kg}$ [10-12]. The mean time taken by LEV and VPA to control seizure was $33.46 \mathrm{~min}$ and $37.25 \mathrm{~min}$ respectively ; slightly higher than reported previously for LEV (mean time: 25-30 min) [20] and SVA (median time: 5 minutes) [11]. The difference could be due to higher loading dose $(50 \mathrm{mg} / \mathrm{kg}$ ) used for LEV in these studies and use of these drugs as first line. We observed a seizure recurrence rate of 50\% in LEV and 57.5\% in VPA group within 24 hours of admission, this was higher than that observed previously $[26,27]$. This difference could be due to longer duration of seizure episode at presentation in our study. After 24 hours of infusion, the two drug groups had similar response rates (66.7\% versus 68.4\%). Overall outcome had no significant difference among the two groups. The higher mortality rate $(30 \%)$ in our study is attributed to late referral and higher incidence of acute symptomatic etiology, as seen in previous study [27].

We observed that, both drugs were tolerable with respect to vital parameters, no significant between-group difference was observed (Figure). No serious adverse events was noted with any group. We conclude that LEV is as effective as VPA with respect to outcome measures [28]. LEV can be as a first drug to control RSE in children before induction of general anaesthesia.

\section{Conflicts of Interest}

The authors declare that they have been no financial or other conflicts of interest in relation to this research and its publication.

\section{Drawback of the Study}

Due to lack of EEG/video EEG facility at our centre, none of the patients were monitored for electroencephalographic termination of seizure.

\section{Acknowledgement}

We acknowledge all parent and children participated in this study.

\section{Bibliography}

1. Trinka E., et al. "A definition and classification of status epilepticus: report of ILAE Task Force on classification of status epilepticus". Epilepsia 56 (2015): 1515-1523.

2. Hussain N., et al. "Aetiology, course, and outcome of children admitted to paediatric intensive care with convulsive status epilepticus: A retrospective 5-year review". Seizure 16 (2007): 305-312.

3. Chin RF., et al. "A systematic review of epidemiology of status epilepticus". European Journal of Neurology 11 (2004): 800810.

4. Fernandez IS., et al. "Gaps and opportunities in refractory status epilepticus research in children: A multi-center approach by the Pediatric Status Epilepticus Research Group (PSERG)". Seizure 23 (2014): 87-97.

5. Holtkamp M., et al. "Predictors and prognosis of refractory status epilepticus treated in a neurological intensive care unit". Journal of Neurology, Neurosurgery, and Psychiatry 76 (2005): 534-539.

6. Mayer SA., et al. "Refractory status epilepticus: frequency, risk factor and impact on outcome". Archives of Neurology 59 (2002): 205-210.

7. Sahin M., et al. "Outcome of severe refractory status epilepticus in children”. Epilepsia 42 (2001): 1461-1467.

8. Saz EU., et al. "Convulsive status epilepticus in children: Etiology, treatment protocol and outcome". Seizure 20 (2011): 115118.

9. Sreenath TG., et al. "Lorazepam versus diazepam-phenytoin combination in the treatment of convulsive status epilepticus in children: A randomized controlled trial". European Journal of Paediatric Neurology 14 (2010): 162-168. 
10. Agarwal P., et al. "Randomized study of intravenous valproate and phenytoin in status epilepticus". Seizure 16 (2007): 527532.

11. Mehta V., et al. "Intravenous sodium valproate versus diazepam infusion for thecontrol of refractory status epilepticus in children: a randomized controlled trial". Journal of Child Neurology 22 (2007): 1191-1197.

12. Malamiri RA., et al. "Efficacy and safety of intravenous sodium valproate versus phenobarbital in controlling convulsive status epilepticus and acute prolonged convulsive seizures in children: a randomised trial". European Journal of Paediatric Neurology 16 (2012): 536-541.

13. Trinka E., et al. "and Safety of Intravenous Valproate for Status Epilepticus: A Systematic Review". CNS Drugs 28 (2015): 623639.

14. Crepeau AZ and Treiman DM. "Levetiracetam: a comprehensive review". Expert Review on Neurotherapy 10 (2010): 159171.

15. Gallentine WB., et al. "Levetiracetam in children with refractory status epilepticus". Epilepsy Behavior 14 (2009): 215-218.

16. McTague A., et al. "Intravenous levetiracetam in acute repetitive seizures and status epilepticus in children: experience from a children's hospital". Seizure 21 (2012): 529-534.

17. Lee Y., et al. "Intravenous levetiracetam versus phenobarbital in children with status epilepticus or acute repetitive seizures". Korean Journal of Pediatrics 59 (2016): 35-39.

18. Goraya JS., et al. "Intravenous levetiracetam in children with epilepsy". Pediatric Neurology 38 (2008): 177-180.

19. Ng YT., et al. "Intravenous levetiracetam in children with seizures: a prospective safety study". Journal of Child Neurology 25 (2010): 551-555.

20. Kirmani BF., et al. "Role of intravenous levetiracetam in acute seizure management of children". Pediatric Neurology 41 (2009): 37-39.

21. Reiter PD., et al. "Intravenous levetiracetam in the management of acute seizures in children". Pediatric Neurology 43 (2010): 117-121.

22. Michaelides C., et al. "Tolerability and dosing experience of intravenous levetiracetam in children and infants". Epilepsy Research 81 (2008): 143-147.

23. Alvarez V., et al. "Second-line status epilepticus treatment: Comparison of phenytoin, valproate, and levetiracetam". Epilepsia 52 (2011): 1292-1296.

24. Mishra D., et al. "Consensus guidelines on management of childhood status epilepticus". Indian Pediatrics 51.12 (2014): 975-990.
25. Lingappa L., et al. "Clinical profile and outcome of refractory convulsive status epilepticus in older children from a developing country". Seizure 36 (2016): 31-35.

26. Chakravarthi S., et al. "Levetiracetam versus phenytoin in management of status epilepticus". Journal of Clinical Neuroscience 22 (2015): 959-963.

27. Misra UK., et al. "Levetiracetam versus lorazepam in status epilepticus: a randomized, open labeled pilot study". Journal of Neurology 259 (2012): 645-648.

28. Glauser TA., et al. "Double-blind placebo-controlled trial of adjunctive levetiracetam in pediatric partial seizures". Neurology 66 (2006): 1654-1660.

\section{Assets from publication with us}

- Prompt Acknowledgement after receiving the article

- Thorough Double blinded peer review

- Rapid Publication

- Issue of Publication Certificate

- High visibility of your Published work

Website: www.actascientific.com/

Submit Article: www.actascientific.com/submission.php Email us: editor@actascientific.com

Contact us: +919182824667 